\title{
ИНСТИТУТ НАЙМА В СОВРЕМЕННОЙ РЫНОЧНОЙ ЭКОНОМИКЕ РОССИИ: ПОСТАНОВКА ПРОБЛЕМЫ И ПОПЫТКА ЕЕ РЕШЕНИЯ С ПОЗИЦИИ ВЕЩНЫХ И ЛИЧНЫХ ПРАВ СОБСТВЕННИКОВ ${ }^{1}$
}

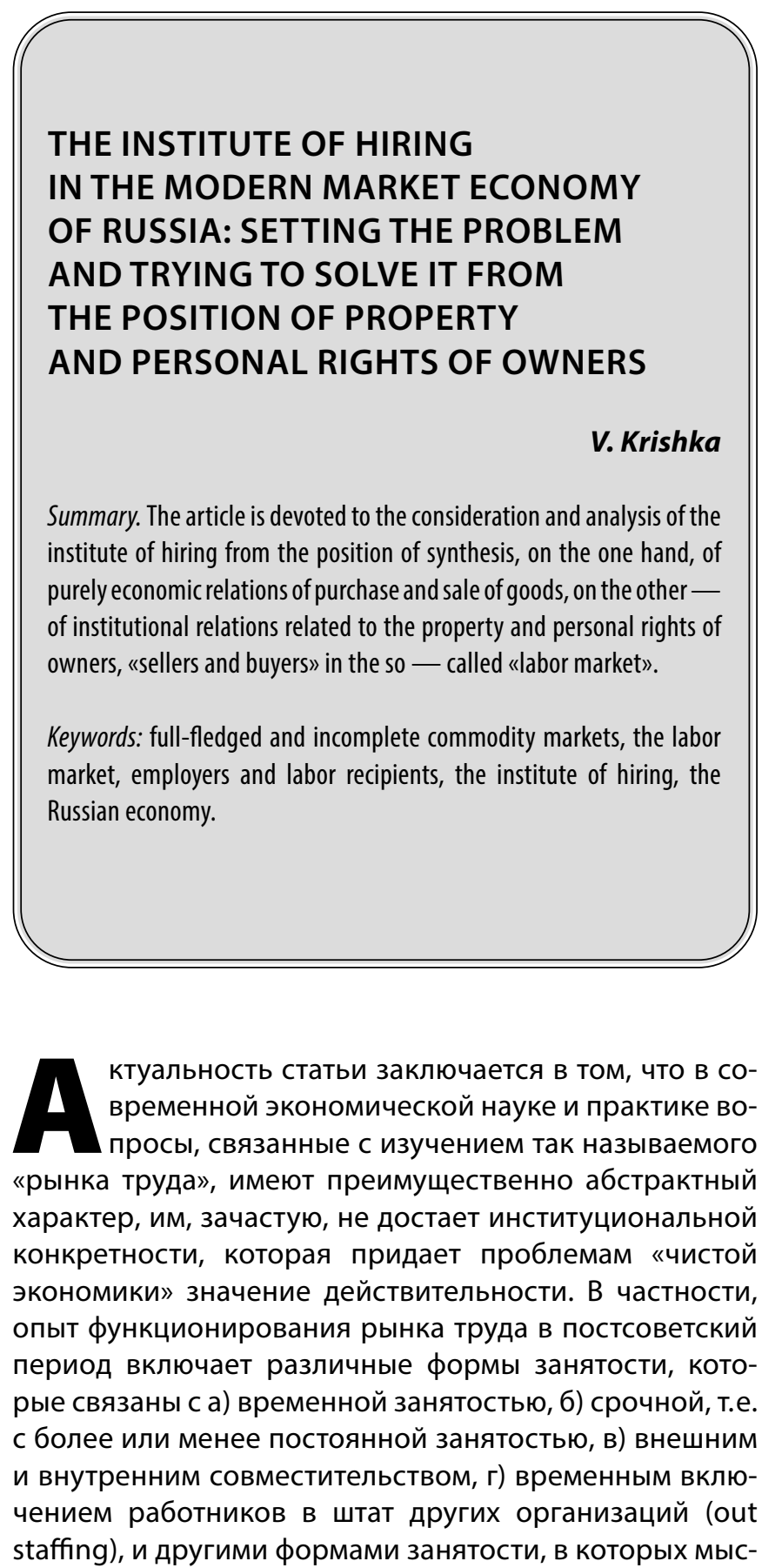

\author{
Крышка Виктор Иванович \\ К.э.н., дочент, ФГБОУ ВО «Алтайский \\ государственный университет» (Барнаул) \\ kryshka@mail.ru
}

Аннотация. Статья посвящена рассмотрению и анализу института найма с позиции синтеза, с одной стороны, чисто экономических отношений купли-продажи товаров, с другой, - институциональных отношений, Связанных с вещными и личными правами собственников, «продавцов и покупателей» на так называемом «рынке труда».

Ключевые слова: полноценные и неполноценные товарные рынки, рынок труда, работодатели и работополучатели, институт найма, российская экономика. ленно подразумевается «найм работников» для выполнения тех или иных работ.

\section{Цель статьи}

Исследование найма с позиции института собственности, включая ее экономическое содержание и права (вещные и личные) собственников.

Для достижения поставленной цели в статье решаются следующие задачи.

1. Определение места рынка труда и его видов в системе кругового воспроизводства товарной формы рабочей силы.

${ }^{1}$ Статья подготовлена при финансовой поддержке Российского фонда фундаментальных исследований в рамках научного проекта № $19-010-00491$ «Исследование взаимного влияния уровня оплаты труда и воспроизводства рабочей силы в условиях макроэкономических и институциональных изменений в российской экономике в 1992-2018 гг.». 
2. Рассмотрение актов купли-продажи обычных товаров с позиции экономического содержания и вещного «пучка прав собственности».

3. Проведение сравнительного анализа найма и купли-продажи товаров с позиции вещных и личных прав собственников.

1. Если применить теорию обращения капитала К. Маркса, которая изложена во втором томе «Капитала», [1, с. 75-172.], то полный кругооборот товарной формы рабочей силы [2] можно, на наш взгляд, представить следующим образом:

$$
\begin{aligned}
& \mathrm{T}_{\mathrm{PC}}-Д_{\text {АзП }} \ldots \mathrm{T} \ldots \mathrm{P}-\text { Д }_{\text {Н3П }} \ldots Д_{\text {Р3П }}- \\
& -\mathrm{T}_{\mathrm{C \Pi T}} \ldots \Pi \ldots \mathrm{y}_{\Pi \mathrm{T}}-\mathrm{T}_{\mathrm{BPC}},
\end{aligned}
$$

где $T_{P C}$ - товарная форма рабочей силы; $Д_{A 3 \Pi}-$ авансированная заработная плата; $T$ - процесс труда; $P$ - выполняемая и выполненная в процессе труда «работа» как товар особого рода [3]; Д заработная плата; Д Рзп - располагаемая заработная плата за вычетом из начисленной заработной платы налога на доходы физических лиц (НДФЛ); $T_{C П т}-$ товарная форма средств потребления; $П-$ процесс потребления; $Y_{\text {Пт }}-$ удовлетворенные человеческие потребности; $T_{B P C}-$ воспроизведенная на основе потребления рабочая сила людей.

В модели 1 исходным пунктом является так называемый «рынок труда», который в современной рыночной экономике России, на наш взгляд, включает три вида [4]. Первыци - это внешний рынок труда, который получил отражение преимущественно в неоклассических моделях микроэкономики, основанных на взаимодействии спроса и предложения по фактору труда. Второй - внутренний рынок труда, который формируется внутри экономических и иных организацией по поводу выполнения и оплаты различных работ, имеющих внутреннюю, условно говоря, товарную форму. Третий - это совокупный рынок труда, формирующийся в народном хозяйстве страны, т.е. в экономических и иных организациях различных форм собственности, и связанный с переходом работников с одного рабочего места на другое, с временной безработицей, работой по совместительству, постоянной (пролетариат) и временной занятостью (прекариат) и другими ее формами.

Все названные рынки труда имеют различную проблематику, изучаемую различными авторами, среди которых можно выделить работы В.Гимпельсона и Р. Капелюшникова [5]. Вместе с тем малоизученным аспектом, на наш взгляд, является сравнительный анализ актов купли-продажи товаров на обычном рынке и рабочей силы на рынке труда. Для упорядочивания изложения, разделим это отношение на две стороны и рассмотрим, во-первых, акты купли-продажи товаров с позиции экономического содержания и «вещных прав собственности» [6-7], и, во-вторых, сравним куплю-продажу товаров с наймом работников с позиции «личных прав собственности», т.е. прав работников и иных лиц по отношению к самим себе и своему труду.

2. Под товаром (Т) в данной статье понимается внешний предмет, вещь, которая, благодаря своим свойствам, удовлетворяет какие-либо человеческие потребности [8, с. 95], а под деньгами (Д) - наличное бытие стоимости в виде определенных знаков, например, Р или \$.

По своему объективному содержанию купля-продажа товаров есть двусторонний обмен товара на деньги $T-$ Д и денег на товар Д - T. Если рассматривать куплю-продажу с позиции проиесса обмена, то она на наш взгляд, включает три стадии: 1) взаимодействия спроса и предложения потенциальных покупателей и потенциальных продавцов; 2) реального перехода товаров и денег из рук в руки действующих продавцов и покупателей; 3) окончания указанного перехода, в котором потенциильные продавцы и покупатели на деле становятся действительными продавцами и покупателями, т.е. продавцы продали товар и получили деньги, а покупатели реализовали покупательную способность денег и получили взамен товар.

С позиции собственности ${ }^{1}$ чисто экономическое содержание актов купли-продажи выглядит следующим образом.

Во-первых, на первой стадии (спроса и предложения) между суверенными лицами (потенциальными продавцами и покупателями) происходит заключение договора купли-продажи, по результатам которого оформляется сделка.

Во-вторых, на второй стадии (переход товаров и денег из рук в руки) происходит реализация договора

Собственность в данной статье - это признанная лицами (физическими и юридическими) принадлежность чего-либо кому-либо, опосредованная отношениями лиц друг к другу по поводу указанной принадлежности. На практике бытие собственности (принадлежности) находится в процессе непрерывного становления, связанного со своим возникновением (присвоение) и исчезновением (отчуждение). Сама собственность (принадлежность) в Гражданском кодексе Российской Федерации [9, с. 153] включает права владения, пользования и распоряжения, включая отчуждение. Частная собственность - это форма исключительной, монопольной принадлежности чего-либо кому-либо, включая право злоупотребления вещью, т.е. нанесения вреда имуществу. Частная собственность по своему личностному содержанию может быть совместной (общественной), например, корпоративная собственность, поэтому противопоставление, которое принято с идеологических позиций «научного социализма», частной и общественной собственности - неправомерно. 
купли-продажи, включая выполнение обязательств, связанных с указанной сделкой.

В-третьих, в результате реализации сделки продавец как товаровладелец отчуждает товар и присваивает деньги, а покупатель как владелец денег, наоборот, отчуждает деньги и присваивает товар.

В результате этого двустороннего процесса а) сохраняется в целом институт частной собственности на обеих сторонах процесса купли-продажи; б) изменяется принадлежность товаров и денег, из собственности одних лиц они переходят в собственность других лиц; в) происходит передача всех прав собственности (владения, пользования и распоряжения), или всего «пучка вещных прав собственности» по А. Оноре [10], бессрочHO.

Исходя из отмеченных пунктов, связанных с вещными правами собственников, все рынки необходимо подразделить на два типа: а) полноценный и в) неполноиенные.

На наш взгляд, к полноценному рынку следует отнести все рынки, на которых акты купли-продажи реализуются абсолютно и связаны с передачей от собственников к несобственникам всего «пучка вещных прав собственности» навечно. При этом к данному рынку, на наш взгляд, относится и «рынок живых существ» (растений, животных и самих людей в качестве рабов), которые рассматриваются на нем как «вещи», не обладающие правоспособностью и соответствующими правами.

К так называемому нами неполноценному рынку следует отнести рынки, на которых осуществляется передача не всего "пучка вещных прав собственности», а только их части, с сохранением за собственником, как правило, прав получения дохода и окончательного отчуждения. Примерами данного неполноценного рынка являются аренда недвижимости, прокат движимого имущества, съем жилья, заем денежных средств и многое другое.

3. С формальной стороны так называемый «рынок труда», на котором формируется институт найма, относится по нашей классификации к «неполноценному рынку», если его вообще можно назвать рынком, и включает следующие особенности.

Во-первых, на рынке труда «вещное право собственности» на работников не распространяется, наоборот, законом запрещается использовать людей в качестве рабов. В этой связи здесь действует не вещное право собственников, а личное право собственников, связанное с правами человека, в частности, на принад- лежность людей самим себе. Если применить категории вещного права Гражданского кодекса Российской Федерации, то принадлежность человека самому себе можно трактовать как владение самим собой, использование самого себя, и распоряжение собой, включая частное право злоупотребления собой, причинения вреда самому себе. Поэтому рассматривать этот «рынок» с позиции полноценных товарно-денежных актов купли-продажи, на наш взгляд,-неправомерно.

Во-вторых, личное право собственников (права человека) по отношению к самим себе и к себе подобным людям связано по своему понятию (с тем, что должно быть) преимущественно не с юридическим правом, а с моральным правом, которое имеет личностное, глубоко субъективное значение, основанное на пиетете глубокого, уважительного, как правило, альтруистического отношения между людьми, которое не приемлет отчужденные товарно-денежные отношения, как правило, эгоистически настроенного «экономического человека».

В-третьих, одним из фундаментальных прав личности (человека) является его имманентное право на жизнь, которое выражается в его жизнедеятельноcmu, включая право на труд. Другими словами, право на труд входит в фундаментальные права человека как личности.

Право на труд в современной российской экономике реализуется через институт ${ }^{1}$ занятости, включая а) институты самозанятости, б) занятость по найму и в) предпринимательство, т.е. самозанятость, связанную с использованием наемных работников. Остановимся на институте найма подробнее.

Сам по себе «найм», на наш взгляд,- - это институционально-экономический процесс, предполагающий наличие: а) работополучателей и работодателей как суверенных лиц, принадлежащих самим себе, б) частной собственности работодателей на используемое имущество (оборудование), в) определенного объема работы (товара особого рода), формируемого на внутреннем рынке труда в экономических и иных организациях, включая оборудованные рабочие места и продолжительность рабочего времени (час, день, месяц, год и т.д.) с учетом умелости и интенсивности труда работников, г) денежную цену труда, т.е. заработную плату, включая ставки заработной платы, расценки предусмотренных работ, д) институциональные условия труда и многое другое.

В статье под институтом (от лат. Institutum - установление, обычай, уч реждение, основание) понимается система норм, правил, законов, влияющих на поведение (деятельность) субъектов хозяйствования. 
В частности, в рамках этого института со стороны работополучателя, заключающего договор найма с работодателем, за ним сохраняется принадлежность самому себе, включая его владение самим собой, использование себя в процессе труда, распоряжение собой на отведенном рабочем месте во время работы в периоды регламентированных перерывов, право на получение дохода в виде заработной платы, охрану труда, исключая вредное использование своего труда и самого себя и т.д. Передает работодателю право управления, точнее, функцию контроля (надзора) над собой в качестве исполнителя нормированных и ненормированных заданий в соответствии с полученной квалификацией, приобретает обязательства своевременного прихода и ухода с работы, рационального использования рабочего времени, сырья, материалов, орудий труда, обслуживания рабочего места и пр. Наемный рабочий является сувереном самого себя, поэтому он может прекратить трудовой договор по собственному желанию в установленные Трудовым кодексом Российской Федерации сроки.

Со стороны работодателя при заключении договора найма работодатель сохраняет за собой собственность на средства производства, включая оборудованные и обеспеченные сырьем рабочие места, изготовленный продукт для окончательной продажи на внешних для экономических и иных организаций рынках, инфраструктуру и многое другое, входящее в вещное право. Передает наемным труженикам права временного использования своего имущества (оборудования) и обязанность качественной обработки и переработки предметов труда, управления наемным трудом (наемный менеджмент) и многие др. права. Получает обязательства своевременной оплаты труда, охраны труда и пр. обязанности, прописанные в трудовых договорах.

В институте найма, который сложился в постсоветский период, можно выделить следующие особенности.

И работополучатель, и работодатель рассматриваются как независимые, свободные, т.е. суверенные физические и юридические лица, имеющие право прекращения (разрыва) и перезаключения (пролонгации) трудового договора, точнее, договора найма в соответствии с действующим законодательством. При этом работополучатель является частным собственником своей личности в целом, включая свою неотчуждаемую рабочую силу, ее реализацию в процессе труда (рабочего времени), а работодатель выступает частным собственником своих средств производства. Этот факт можно трактовать, в зависимости от идеологических пристрастий, как с позиции марксисткой эксплуатации, обращая при этом внимание на так называемое «наем- ное рабство», и либерализма, обратив внимание, на то, что найм предполагает «освобождение» работника от бремени собственности и концентрации внимания работника на развитии своего человеческого капитала, значение которого возрастает параллельно с развитием вещественного капитала в виде роботизации производственных и иных процессов.

Современный работополучатель в институте найма сохраняет за собой права а) владения самим собой в соответствии со сложившейся системой разделения труда в экономической организации и обществе; б) $c a$ моиспользования (производительного потребления) самого себя в соответствии с регламентом рабочего и внерабочего времени, в) самораспоряжения (управления) самим собой в рамках рабочего места и полученной квалификации, г) получения располагаемого дохода в виде начисленной оплаты труда за минусом социальных страховых взносов и НДФЛ и плюсом различных доплат (например, социальные выплаты), непосредственно не связанных с работой в организации.

Современный работодатель в институте найма сохраняет за собой право владения имуществом, включая основные и оборотные средства, используемые работниками, имеет право расчета с внешними организациями, включая а) вычеты из фонда оплаты труда, б) получение выручки, частью которой с позиции оборота средств организаций является фонд оплаты труда и т.д.

Работодатели как некий «идеологический класс» по согласию с работополучателями в современной экономике де факто получили право временной передачи рабочей силы в распоряжение (управление) других работодателей (out staffing) на «правах аренды», хотя этот термин в данном случае можно использовать весьма условно. Аренда относится в вещественному, а не личному праву, поэтому лучше говорить - на правах субнайма, т.е. временной передачи права управления работниками другим работодателям.

Работополучатели как «идеологический класс» (пролетариат) де факто и де юре имеют права а) перехода с одного рабочего места на другое в рамках одной организации, б) от одного работодателя к другому, в) временного трудоустройства (прекариат) без заключения трудового договора и привязки к конкретному работодателю, г) изменения своего социально-экономического статуса, перехода в группу самозанятых и предпринимателей и другие права.

Наконец, в современной экономике России в институт найма в целом можно включить свободный выбор будущей профессии, профессиональную подготовку ка- 
дров для соответствующего трудоустройства, постоянное или временное трудоустройство, службы занятости, пособия по безработице, переквалификацию кадров, стаж работы, пенсионное обслуживание, соответствующие юридические и иные нормы и многое другое.

В заключении данной статьи можно сделать следующие выводы:

Во-первых, исходным и конечным пунктом воспроизводства в самом широком смысле является сфера обращения (рынок). В статье действительный рынок с позиции собственности, ее экономического содержания и юридических прав, подразделен на два типа: на полноценный и неполноценный рынки. На первом рынке в актах купли-продажи товаров происходит передача всего «пучка прав собственности» от собственников несобственникам, а на втором - только части прав, с сохранением, как правило, за собственниками прав получения дохода и отчуждения, прекращения права собственности в целом.

Во-вторых, так называемый «рынок труда», если использовать терминологию вещного права, относится ко второму типу, наряду с арендой, прокатом, займом и т.п. Точнее, на этом рынке происходит не купля-продажа, например, труда или рабочей силы, а найм работников, который регулируется со стороны собственников имущества отчасти вещными правами собственников, а со стороны работника - личными правами собственников, входящими в самом широком смысле в права человека.

В-третьих, с экономико-юридической точки зрения найм - это сложный процесс (акт) взаимодействия суверенных лиц (работополучателей и работодателей), связанный с временным или постоянным трудоустройством, выполнением оплачиваемой работы и получением заработной платы за выполненную работу, которая является своеобразным товаром на внутреннем рынке труда экономических и других организаций. В частности, наемный работник при заключении трудового договора и его исполнения сохраняет за собой право принадлежности самому себе, но передаёт работодателю на время работы право управления собой (контроля, надзора за своей работой), в которой используются не принадлежащие ему (чужие) средства производства.

В-четвертых, в статье сделана попытка рассмотрения института найма в самом широком смысле, который включает свободу выбора будущей профессии, профессиональную подготовку кадров, постоянное или временное трудоустройство, службы занятости, наставничество, пособия по безработице, переквалификацию кадров, стаж работы и пенсионное обслуживание, юридические, моральные и идеологические нормы, связанные с наймом. В этой связи институт найма можно трактовать, в зависимости от идеологических пристрастий, и как с позиции марксисткой эксплуатации, обращая внимание при этом на так называемое «наемное рабство», так и с позиции либерализма, обратив внимание на то, что найм предполагает «освобождение» работника от «бремени собственности» и концентрацию внимания работника на развитии своего человеческого капитала.

В-пятых, «отчуждение труда» как проблема марксисткой политической экономии, изложенная в работах [11-17], исходя из содержания статьи, не лишена идеологического смысла, но лишена подлинного научного содержания. Идеологический смысл проблемы «отчуждения труда», если оставить в стороне чисто экономическое содержание, своими корнями уходит в «фетишизацию труда», когда труд рассматривается не как функция человека, а наоборот человек превращается в функцию ТРУДА. Идеология «научного социализма и коммунизма» К. Маркса и Ф. Энгельса исходит, как представляется, именно из этого перевертыша.

\section{ЛИТЕРАТУРА}

1. Маркс К. Капитал: критика политической экономии. Т. ІІ: [пер. с нем., фр., англ.] / Карл Маркс; [предисл. Л.Л. Васиной, В.С. Афанасьева; послесл. В.И. Маевского]. - М.: Эксмо, 2012. - 1200 с.

2. Крышка В.И., Перекаренкова Ю.А., Солопова Н.Н. Положительные и отрицательные эффекты воспроизводства рабочей силы в постсоветский период российской экономики // Финансовая экономика. - 2020. — № 10, ч. 1.—C. 45-50.

3. Крышка В.И. Конструктивно-критическая верификация теоретической модели кругооборота товарной формы рабочей силы в постсоветский период современной // Современная наука: Актуальные проблемы теории и практики. Серия «Экономика и право». — 2020. — № 6, — С. 48-53.

4. Крышка В.И., Ан Е.А., Зорин А.С., Перекаренкова Ю.А. Воспроизводство рабочей силы в российской экономике постсоветского периода: проблемы занятости, безработицы и миграции // Экономика. Профессия. Бизнес. - 2020.— № 4. — С. 67-75.

5. Российский рынок труда: тенденции, институты, структурные изменения / под ред. В. Гимпельсона, Р. Капелюшникова и С. Рощина.— М., 2017. 148 c.

6. Шкредов В.П. Принципы исследования производственных отношений в связи с юридической формой их выражения [Текст]: Автореферат дис. на соискание ученой степени доктора экономических наук / Моск. гос. ун-т им. М.В. Ломоносова. — Москва: Изд-во Моск. ун-та, 1968. -35 с. 
7. Орехов В.М., Чаплыгина И.Г. Категория собственности и экономическая теория // Онтологические предпосылки экономических теорий: сборник / Под. ред. О.И. Ананьина. - М.: ИЭ РАН, 2011.- С. 54-95.

8. Маркс К. Капитал: критика политической экономии. Т. І.: [пер. с нем., фр., англ.] / Карл Маркс; [введ. О.И. Ананьина; предисл. Л.Л. Васиной, В.С. Афанасьева]. - М.: Эксмо, 2012. - 1200 с.

9. Гражданский кодекс Российской Федерации (части первая, вторая, третья, четвертая): По состоянию на 1 февраля 2021 года. — Новосибирск: Норматика, 2021.- 608 c.

10. Honore A.M. Ownership // Oxford essays in jurisprudence / Ed. by A.W. Guest. — 0xford, 1961. — C. 112—128.

11. Пажитнов Л.Н. У истоков революционного переворота в философии. - М., 1960.- 172 с.

12. Кешелава В.В. Миф о двух Марксах. - М., 1963. - 119 с.

13. Курелла А. Свое и чужое: новое к проблеме социалистического гуманизма / Пер. с нем. Т.А. Рябушкиной и Л.А. Киселевой; под ред. и с пред. А.С. Богомолова. - М., Издательство «Прогресс», 1970. — 280 с.

14. Нарский И.С. Отчуждение и труд: По страницам произведений К. Маркса. — М.: Мысль, 1983. - 144 с.

15. Ойзерман Т.И. Формирование философии марксизма. - М.: Мысль, 1986. - 462 с.

16. Кальной И.И. Отчуждение: истоки и современность. - Симферополь: Таврия, 1990. - 192 с.

17. Чангли И.И. Труд. Социологические аспекты теории и методологии исследования: монография. — Издание 4-е. - М.: ЦСП и М, 2010. — 608 с.

( ) Крышка Виктор Иванович ( kryshka@mail.ru ).

Журнал «Современная наука: актуальные проблемы теории и практики»

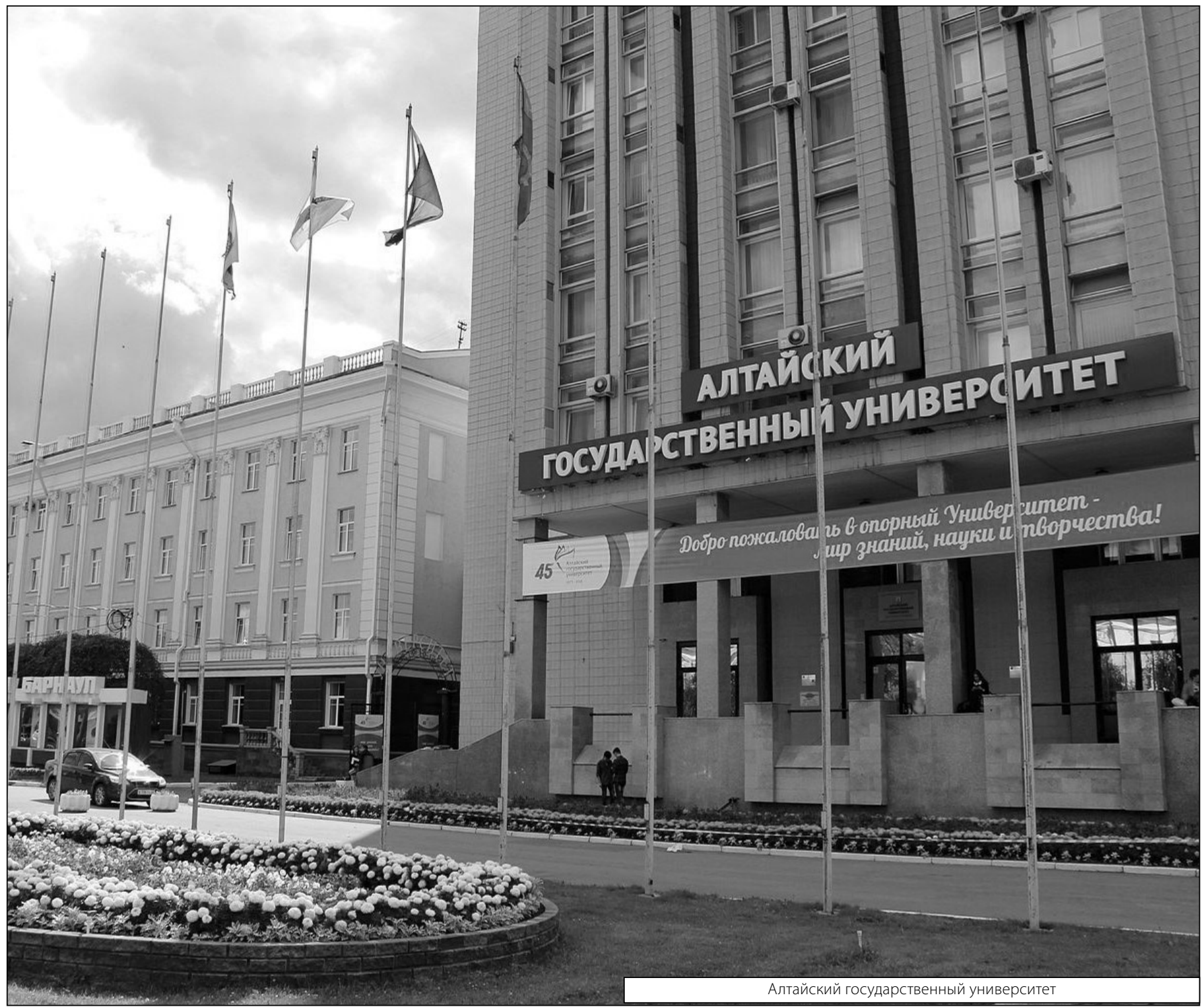

